\title{
Acontecer de la copia: apuntes para el estudio de las máquinas piratas ${ }^{1}$
}

\author{
Fernando Ruiz Molina ${ }^{2}$
}

Recibido: 29/04/2021; Aceptado: 20/09/2021

Cómo citar: Ruiz Molina, F. (2021). Acontecer de la copia: apuntes para el estudio de las máquinas piratas. Revista Hipertextos, 9(16), 35-54. https://doi.org/10.24215/23143924e039

Resumen. El presente trabajo es producto de una incursión a una parte del insondable mundo de las piraterías, con el propósito de conceptualizar sus quiebres, movimientos y operaciones, a partir de la observación de las transformaciones y distorsiones experimentadas en la degradación, adecuación, extracción, desterritorialización y reterritorialización de los componentes semióticos de un mismo objeto en el acontecer de su copia, y su posterior conceptualización. A este proceso lo postulamos pirataje. Estos piratajes, efectos que a su vez detonan otros objetos-copia (alterando la producción) ad infinitum. El presente artículo deriva de una investigación doctoral que tuvo por objeto el estudio y descomposición de las operaciones de fijación (desterritorialización y reterritorialización) perseguidas por el régimen vigente, así como la descomposición de los objetos producidos y copiados que, no necesariamente son en sí mismos ilegales, a priori, sino ilegalizados (a través de restricciones y discursos político-comerciales temporales). Además del análisis de un cuerpo de manifiestos piratas y otras etnografías, el presente artículo se trata de un trabajo introductorio a los Estudios sobre Piraterías y Modernidades Piratas, y ofrece una perspectiva que no sólo deconstruye y permite pensar al fenómeno desde su potencial estético, sino en relación a las dinámicas, movimientos y operaciones de un capitalismo que ha devenido semiótico, con dinámicas de valorización y revalorización, y formas de explotación mucho más recrudecidas. La piratería es el espejo de este dicho estadio.

Palabras clave: piratería, pirataje, culturas de la copia, apropiación, cultura popular global

Sumario. 1. Introducción: la piratería como objeto de estudio. 2. Modernidades Piratas. 3. Pirataje: reformulando la piratería. 4. Fases del proceso de pirataje. 5. Estrategias Interventivas. 6. Efectos posibles: sabotaje, fruición, engaño. 7. Conclusión: nuevos horizontes del pirataje.

\footnotetext{
${ }^{1}$ Este artículo emana de un trabajo de investigación doctoral realizado entre 2013-2017.

2 Doctor en Comunicación y Política por la Universidad Autónoma Metropolitana-Unidad Xochimilco. Colaborador y miembro del Círculo de Estudios sobre Subcultura Japonesa en México (CESJM), en donde hace investigación sobre China y Japón. Corresponsable del Seminario Japón y los Imaginarios Culturales, del Posgrado en Antropología Social (Escuela Nacional de Antropología e Historia) y el CESJM, con sede en Museo Nacional de las Culturas del Mundo-INAH. Docente en el Posgrado de Antropología Social de la ENAH, la Universidad Autónoma de la Ciudad de México y la Universidad Autónoma Metropolitana-Iztapalapa. Sus líneas de investigación son las Piraterías y las Modernidades Piratas, los Afectos, el Urbanismo Media, los Estudios Japoneses, así como la cultura popular asiática contemporánea. Contacto: ruizfer.mol@gmail.com / fernando.ruizm@enah.edu.mx
} 


\title{
Event of the Copy: notes for the study of Pirate Machines
}

\begin{abstract}
The present work is the product of an incursion into a part of the unfathomable world of piracy, with the purpose of conceptualizing its breaks, movements and operations, based on the observation of the transformations and distortions experienced in the degradation, adaptation, extraction, deterritorialization and reterritorialization of the semiotic components of the same object in the event of its copy, and its subsequent conceptualization. We postulate this process as pirataje. These pirataje, effects that in turn detonate other objects-copy (altering production) ad infinitum. This article derives from a doctoral research that aimed the study and decomposition of the fixing operations (deterritorialization and reterritorialization) pursued by the current regime, as well as the decomposition of the objects produced and copied, which are not necessarily in themselves illegal, a priori, but illegalized (through temporary political-commercial restrictions and speeches). In addition to the analysis of a body of pirate manifestos and other ethnographies, this article is an introductory work to the Studies on Piracy and Pirate Modernities, and offers a perspective that not only deconstructs and allows us to think about the phenomenon from its aesthetic potential, but in relation to the dynamics, movements and operations of a capitalism that has become semiotic, with valorization and revalorization dynamics, and much more intensified forms of exploitation. Piracy is the mirror of this stadium.
\end{abstract}

Keywords: piracy, pirataje, copy cultures, appropriation, global popular culture

\section{Acontecimento da cópia: notas para o estudo de máquinas piratas}

Resumo. Este trabalho é o produto de uma incursão por uma parte do mundo insondável da pirataria, com o propósito de conceituar suas rupturas, movimentos e operações, a partir da observação das transformações e distorções vivenciadas na degradação, adaptação, extração, desterritorialização e reterritorialização dos componentes semióticos de um mesmo objeto na ocorrência de sua cópia, e sua conceituação subsequente. Nós postulamos esse processo de pirataje. Esses piratajes, efeitos que por sua vez detonam outros objetos-cópia (alterando a produção) ad infinitum. Este artigo é fruto de uma pesquisa de doutorado que teve como objetivo estudar e decompor as operações de fixação (desterritorialização e reterritorialização) perseguidas pelo regime atual, bem como a decomposição dos objetos produzidos e copiados que eles não são necessariamente ilegais em si mesmos, a priori, mas ilegalizados (por meio de restrições e discursos político-comerciais temporários). Além da análise de um corpo de manifestos piratas e outras etnografias, o artigo é uma obra introdutória aos Estudos sobre Pirataria e Modernidades Piratas, e oferece uma perspectiva que não só desconstrói e permite pensar o fenômeno a partir de seu potencial estético, mas também em relação às dinâmicas, movimentos e operações de um capitalismo que se tornou semiótico, com dinâmicas de valorização e revalorização, e formas de exploração muito mais exacerbadas. A pirataria é o espelho desse estádio.

Palavras-chave: pirataria, pirataje, culturas de cópia, apropriação, cultura popular global

\section{Introducción: la piratería como objeto de estudio}

Cuando estudiamos el fenómeno de la piratería contemporánea, lo primero que percatamos es que no existe claridad en los límites materiales y tempo-espaciales de lo legal e ilegal, lo formal e informal, lo lícito e ilícito, el original y la copia, profundidad y superficie. Al parecer, las fronteras desde donde se despeja lo que es o no es piratería, han sido impuestas a conveniencia de ciertos grupos de interés transnacionales y poderes fácticos 
Los cuales cabildean ... activamente ante sus gobiernos en busca de penas más rigurosas en contra de la piratería de productos, y emprenden campañas para deslegitimar y criminalizar (de diversas formas) esas actividades (y a sus sujetos) (Alba Vega, Lins Ribeiro, Mathews, 2015, p. 28; los paréntesis son míos).

Además de la dificultad para definir qué es y qué no es piratería, sin reducir el fenómeno a sólo un asunto derivado de la infracción del derecho de propiedad, multiplicación, exclusividad de explotación y/o reproducción, debemos considerar la imposible homogeneidad de la piratería (Lobato, 2014), es decir, su proteico acontecer y la amplia gama de prácticas, sujetos, estrategias, artefactos, ecosistemas, entornos y objetos que la componen; elementos que asignan al pirata todo tipo de "roles (aparentemente) incompatibles: empobrecedor informacional, ladrón reacio, ahorrativo innovador, empresario de base, oportunista digital" (Lobato, 2014, p.128, los paréntesis son míos), liberador informacional y creador de accesos, emprendedor de bajo costo, re-integracionista y/o reciclador de artefactos semióticos, impostor y/o defraudador, canal de dispersión, agente globalizador de bajo costo, creador de ecosistemas alternativos/complementarios (o de reaprovechamiento), re-apropiacionista y adaptador cultural, especulador del necrocomercio, etc.

En diferentes momentos y contextos, la piratería puede jugar uno o más de estos roles, o todos al mismo tiempo: estrategia de acceso cultural, lugar de resistencia y respuesta, vía rápida de enriquecimiento bajo la lógica neoliberal, canal de alta velocidad y diseminación, etc.

La gran cantidad de prácticas y campos en apariencia disímiles y contradictorios que engloba la piratería, desborda los intentos hasta ahora realizados de registro y clasificación de la misma. Desde el plagio, la sustracción de originales para su posterior reubicación y venta en los circuitos informales, la reproducción parcial o total de un original, la descarga de torrent, o la digitalización y posterior subida de un libro a ciertas plataformas online. Cada uno de estos aconteceres de la piratería supone técnicas, herramientas, tácticas, estrategias de apropiación y negociación de lo auténtico, trabajo y juegos sígnicos, flujos y circuitos de circulación distintos, condiciones extratextuales específicas (intencionalidad, personalidad, ideas sobre "lo común", búsqueda de ventaja o realización bajo los esquemas culturales vigentes), modos de ser, etc. Todos corresponden a una cuestión de infracción de los regímenes de copyright, pero explicarlos solamente desde la perspectiva de lo legal e institucional deja fuera aspectos estéticos, socioeconómicos, filosóficos, políticos y culturales reveladores del sistema.

La piratería es paradójica: existe porque el sistema económico vigente alberga, detona y permite la copia y sus tecnologías de reproducción en aras de un supuesto conocimiento y progreso, como consumo integral, reificación y conservación del orden mismo. Pero castiga y persigue la multiplicación o disposición de estos objetos para usufructo pecuniario o individual (Lord Mansfield en Lessig, 2004, p.17), toda vez que queda instaurado en piedra un régimen autoral de vigilancia sobre los prototipos o modelos, y sus descontentos.

Estos regímenes globales de propiedad intelectual, generalmente, criminalizan a los más desfavorecidos del sistema-mundo ${ }^{3}$ : excluidos de los flujos, experiencias y objetos del comercio

${ }^{3}$ Laikwan Pang (2006) define a estos regímenes como maquinarias de carácter global, en capacidad de constante reajuste, interconexión y comunicación entre sí, destinadas a regular la propiedad intelectual y el copyright en cada rincón y flujo del planeta: Intellectual Property Rights (IPR). Pang apunta que estas maquinarias colocan, con suma estrategia, cada uno de sus dispositivos panópticos: las patentes, trademarks, tratados secretos y copyrights. Con ellos, advierte Pang, no sólo se regula el tránsito, velocidades, intercambios y usos "permitidos" para esas ideas o conjuntos de éstas, artefactos u objetos, sino también lo que deber ser recordado y olvidado, además de establecer 
legal/oficial, quienes, a través de sus medios y desde sus limitaciones, se insertan en el impulso globalizante de la moda y la lógica imperante del mercado, a través de lo que llamamos actos de pirataje, interceptando, copiando y distribuyendo originales sin autorización, o adquiriendo mercancías falsificadas o sustraídas y reposicionadas en distintos circuitos informales, o bien, integrando la máquina del comercio informal (Alba Vega et al., 2015; Pang, 2006) ${ }^{4}$.

A pesar de que se da por hecho que quienes consumen o incurren en actos de piratería provienen de los sectores de menores ingresos de la sociedad, lo cierto es que los estratos con poder adquisitivo también incurren en dichos actos, es decir: la omisión o torsión de ciertas reglas para evadir impuestos, o bien el despojo a ciertos grupos no hegemónicos (o fuera del poder) de sus conocimientos, materialidades, estéticas y sentidos o patrimonios inmateriales para revalorizarlos, patentarlos y explotarlos comercialmente, ora saboteando de diversas maneras, a través de distintas piraterías cibernéticas, a otras instancias ${ }^{5}$.

Dada la compleja naturaleza de la piratería, su acontecer, incidencia, y el desafío metodológico que representa su estudio, y en base a una investigación doctoral, nosotros proponemos la distinción entre pirataje y piratería: mientras que la piratería es pensada como flujo o circuito, el pirataje es el dispositivo maquinal que lo corta/produce, funda y transforma. Cada piratería (independientemente de su expresión material/concreta) es precedida y contiene un pirataje distinto: desde una forma precisa de evasión de la norma ${ }^{6}$, la intercepción de un flujo legal u objeto original para sustraer/extraer/copiar de él elementos que serán evocados y/o colocados en otras mercancías, objetos o flujos, para ser re-comercializados sea como imitaciones, o como supuestos originales; hasta el hurto o apropiación hegemónica de un conocimiento o saber

qué se consume, lee, mira, come, etc., y cómo debe (o no) ser experienciado y/o usado; "la protección legal de databases (extensiva a todo el globo) puede crear fácilmente un monopolio de conocimento, por lo tanto, limitar severamente las maneras en que las personas pueden acceder y hacen uso de la información (y otros materiales para la creatividad)" (Pang, 2006, p.19; los paréntesis son míos). Pang también apunta que se trata de modelos que conciben que la cultura puede ser practicada y cuantificada económicamente, y que suponen a la autoría no sólo como algo natural, sino medible y divisible (2006, p.27). Son modelos de aplicabilidad internacional (TRIPs: TradeRelated Aspects of Intellectual Property Rights), como la DMCA (Digital Millenium Copyright Act) con sede en los Estados Unidos, a lo regional, como los tratados de libre comercio (NAFTA 2.0: North American Free Trade 2.0), además de las regulaciones locales.

${ }^{4}$ Algunos grupos y consultorías como el denominado "Centro de Estudios de Telecomunicaciones sobre América Latina", han publicado reportes sobre piraterías, como el relacionado a contenidos audiovisuales online de noviembre de 2019 a marzo de 2020, en donde señalan un incremento considerable de consumo pirata en la región de América Latina (siendo relevantes los casos de México, Brasil, Colombia y Venezuela) (disponible en: https://cet.la/estudios/cet-la/dimension-e-impacto-de-la-pirateria-online-de-contenidos-audiovisuales-en-americalatina/). Aunque estos reportes ofrecen indicios sobre el panorama, en su mayor parte enfocan el fenómeno sólo en regiones del denominado Sur Global, acudiendo a lo que Kavita Philip (2005, 2012) denomina como tecnoesencialismos, es decir, la distinción esencializada entre países atrasados o subdesarrollados que aspiran a la ciudadanía global, y aquellos que ya la poseen y ocupan una posición de autor global privilegiada, distinción en la que operan imaginarios de "raza, clase, género, colonialismo" (2008, p.79), e "higiene, modernidad, progreso" y tecnología (2012, p. 36); como apuntan otros informes y estudios (Karaganis, 2012), las piraterías de mercancías sustraídas o falsificadas, así como de contenido digital, también ocurren dentro del denominado Norte Global (desde Canal Street en NY, hasta las principales calles de Barcelona) (https://www.theregreview.org/2021/08/28/saturday-seminar-combating-counterfeit-goods-e-commerce/); tras declarada la emergencia internacional por COVID19, las formas de su circulación no sólo se han visto modificadas (especialmente a través de e-commerce) sino también aceleradas. (https://www.worldtrademarkreview.com/anticounterfeiting/counterfeiting-and-piracy-in-2021-the-global-impact)

${ }_{5}$ Alba Vega, Lins Ribeiro y Mathews (2015) enuncian estos dos polos como globalización desde abajo (ambulantaje, comercio informal, contrabandistas y copiadores ocasionales) y, globalización desde arriba (firmas, emporios y figuras hegemónicas que extractivizan las semióticas, fuentes de sentido y culturas de los pobres, como una suerte de mina, en la constante commodification $o$ mercantilización).

${ }^{6}$ Como sucede en el caso del plagio, o el soborno, en el caso de la vendimia y consumo de alcohol en la calle, entre otros.

Hipertextos, Vol. 9, N 16. Buenos Aires, Julio/Diciembre de $2021 \ll 38$ https://doi.org/10.24215/23143924e039, https:// revistas.unlp.edu.ar/hipertextos 
inmaterial cuya comercialización puede traducirse en cuantiosas ganancias (como es el sonado caso de las piraterías de diseños autóctonos, etc.). Esta relación, pirataje-piratería, es lo que hemos concebido, metodológicamente, y desde una perspectiva deleuzeana, como máquina pirata ${ }^{7}$. Cada máquina-pirata posee una lógica distinta, y obedece a un objeto y orden específicos.

No son lo mismo la piratería de textos (por fotocopiado, o impresión sin licencia de un texto), y el plagio de textos (que implica la sustracción de ideas, sistematizaciones conceptuales y hallazgos para ser colocados en otro texto, al que se hace pasar como propio para obtener beneficios). Como veremos más adelante, debe darse cuenta del estatuto de copia, imitación, simulacro o replicación presente en el tipo de piratería en cuestión, según el proyecto de autenticidad aludido ${ }^{8}$, campo o momento de la producción que es objeto de la inflexión del pirataje.

La piratería no puede ser pensada en términos homogéneos, ni como algo exclusivo de una clase social, para cada flujo de objetos o fenómenos piratas, hay una disposición de prácticas, operaciones y estrategias (de omisión, sustracción, extracción o copia), y atmósferas y espacios codificados que pueden llegar a rivalizar ${ }^{9}$. No hay piratería sino piraterías. Asumiendo esta diversidad, y diferenciando entre piraterías y actos de pirataje, es posible despejar una de las problemáticas clásicas de los estudios de las piraterías, y diferenciar: por un lado quienes parten de cierto "copyrightcentrismo" (Lobato, 2014) y ponen demasiado peso al cómo sucede la infracción legal, reduciendo el fenómeno a un asunto de aplicación de la ley, sin necesariamente problematizar los conceptos en juego de acceso, propiedad, pertenencia o autor -incluso en debates de carácter académico- (Pang, 2006, 2015; Lobato, 2014). Y por el otro, la celebración automática del acto pirata como una forma de resistencia y combate a las formas capitalistas (siendo que, a veces, quien despliega un acto pirata desconoce el horizonte normativo o la regla infringida - de ahí el peligro de creer de entrada que se trata de un acto derivado de la consciencia y adscripción de un programa político- $)^{10}$. De este modo, Lobato apunta que es muy usual interpretar la diversidad de actos y prácticas piratas desde cierto lenguaje del media sharing o las

\footnotetext{
7 Una máquina, explican Gilles Deleuze y Félix Guattari (1985), puede ser conceptualizada como un conjunto de disposiciones, interrelaciones y flujos, que cortan e iteran parcial o totalmente sus códigos, alterando tanto la "naturaleza" de los mismos, así como lo que es "cortado". La máquina "es lo que corta y es cortado" (p.47).

8 Proyecto de autenticidad remite a una serie de condiciones, factores y disposiciones económicas, históricas, políticas y sociales, en cuyos entrecruzamientos se determinan vías, prácticas, estrategias, objetos, materialidades, cualidades o propiedades, relaciones y conexiones para alcanzar, producir o performar lo que ha sido convenido como auténtico/autenticidad. Siendo estos sets semióticos o doxas, a su vez, determinantes para el establecimiento de lo que es o no, una fuente para producir, performar o fijar lo auténtico. Estos sistemas no sólo determinan lo que es auténtico, también establecen vías, formas, materias y diagramas de lo inauténtico. La piratería, sin embargo, ofrece inusitadas formas inauténticas para alcanzar lo auténtico, y en algunos casos, es capaz de torcer dicha cualidad para producir otros excedentes significativos y simbólicos.

${ }_{9}$ Como es el caso de los denominadas culturas colaborativas/sharing economies, tildadas como actos piratas por que se ha ilegalizado su acción de compartir, abrir fuentes y materiales creativos, romper candados o liberar contenidos para ponerlos a disposición del público general; y del comercio informal, donde no hay en absoluto una renuncia al leitmotiv de generar y acumular ganancias bajo la lógica capitalista.

10 Desde el dibujamiento romántico del pirata como una suerte de Robin Hood, hasta la asunción automática del hacker como una figura contestataría que busca romper códigos y evidenciar cómo las máquinas son empleadas sistemáticamente para organizar el mundo (Johns, 2009). Eva Hemmungs Wirtén (2006) apunta que el hacker dentro de los discursos que se oponen a la cruda expansión de los IPRs, o que radica en los discursos que promueven la liberación de software e intervención de los códigos y fuentes del sistema cultural, se trata de otra forma romantizada del aura fetichizada del artista ("originalidad, expresión y talento"), cuyos actos, ejercicios, trabajo personal y expresión de "creatividad" y "libertad", es tan sólo la continuación del mito occidental de la creatividad, ignorando la complejidad laboral, u omitiendo el empleo estratégico de la colaboratividad dentro de los nuevos capitalismos informacionales y las economías creativas, como estrategia de apertura, saqueo y absorción de novedades y fuentes, bajo el lema de "conecta, comparte y participa" (Ver también Pang, 2012, p 62).
} 
economías colaborativas -grupos aparentemente relacionales, descentralizados, autogestivos y horizontales de usuarios dispuestos a compartir, abrir sus fuentes y redistribuir sus objetos culturales-, que deja de lado que la piratería también puede erigir estructuras lucrativas, posiciones de poder, y reforzar la lógica neoliberal de la especulación y acumulación de riquezas, porque se le otorga mucho más importancia al supuesto acto de beneficencia de la práctica pirata $^{11}$.

\section{Modernidades Piratas}

Ravi Sundaram (2010) denomina "Modernidades Piratas" al conjunto de condiciones globales de conectividad, tecnologización, desigualdad, exclusión, reciclaje, adaptación, escamoteo, autoinserción y apropiación, que en su interrelacionalidad y mutua afectación dan pauta a: (a) afectos y sensaciones generalizadas de constante colapso, error, desfase, desorientación y fragmentación, (b) objetos y artefactos inéditos, virales y en constante mutación; (c) acontecimientos y formas tecnológicas y culturales urbanas y subalternas que dependen de algunos órdenes y disposiciones informales y a la sombra de las estructuras legales de la "ciudad planeada" o la "ciudad modelo". Los Estudios sobre Modernidades Piratas, han introducido nuevas consideraciones alrededor del data, saturación, riesgo, circulación de objetos culturales, intimidad, velocidad, afecto, ruido e interferencia, apropiación, media, visualidad/sonoridad, espacialidad, atmósfera y materialidad, que confluyen en lo que autores como Brian Larkin (2013) han denominado infraestructuras piratas, o lo que Joshua Neves (2020) nombra como underglobalization.

Estos estudios no pierden de vista las tensiones y problemáticas emergidas en lo ilícito, la ilegalidad, la ilegitimidad y otras prácticas subterráneas, así como en la creatividad mundana y periférica, y sus entrecruzamientos locales y globales. Ponen su énfasis en la estética, el urbanismo, la filosofía y la socioantropología. Sundaram sienta las bases para pensar aquellas subjetividades que por su condición periférica, formas de acceso a los flujos de novedad, realización de promesas y otras tendencias discursivas globales, no encajan en la posición de sujeto emanado de la modernidad, sus proyectos de ciudadanía y democracias (ver Sundaram, 2010 , p. 21). De este modo, nos muestra no sólo estrategias paralegales y no autorizadas implementadas por estos ciudadanos piratas, sino también aquellas que atienden a lo particular y a lo colectivo, desde la copia y la improvisación, hasta la redistribución, torsión de los flujos de distribución y las infraestructuras "oficiales", y la falsificación o el engaño. Esto no sólo implica

\footnotetext{
${ }^{11}$ No son pocos los manifiestos relacionados a la Cultura Libre, Copyleft, Software libre y Acceso libre, entre otros, que permanecen sólo en los aspectos que ellos consideran positivos y transgresores de las piraterías (Lessig, 2004, 2008; GNU, 2018; Stallman 2002, 1997; Wu Ming, 2002, 2003; Liang, 2009). Nicholas A. Johns (2013) señala que existe una semántica compartida entre las sharing economies y las piraterías, con "raíces profundas en el mundo de las computadoras y su matrimonio con un set de valores que tienen que ver con las relaciones interpersonales" (p. 118); donde compartir, participar, conectar, no sólo es concebido como un acto constitutivo de la transparencia, claridad y las relaciones sociales en la época de las plataformas digitales y las infraestructuras colosales de recabación de data (Hall, 2016, p.31), sino como actos de (re)distribución y comunicación, generadores de vínculos afectivos en capacidad de regular la totalidad del tecnosistema (participación pública y colaboración). Por un lado, y bajo este sentido, compartir implica abrir nuestros materiales y las fuentes de conocimiento, un hacer y una ética colectiva para el resguardo y libre ejercer de las creatividades, pero se obvian las marcas materiales previas a la competitividad, infraestructuras de trabajo, disimetrías y posibilidades reales de capitalización de esos materiales, y se invisibilizan algunas de las funciones que la piratería cumple para totalidad de la máquina de máquinas capitalista, en la oscuridad de su potencia subterránea (incluso en esta pretendida modalidad "domesticada" de la piratería que esgrimen estos manifiestos). Mientras estos manifiestos están asociados a una postura infoliberal (Fish, 2017; Spragens, 1999; Hall, 2016), que busca reformar la autoría y la propiedad intelectual, existen posiciones políticas piratas, que por el contrario, buscan la destrucción del sistema espectacular y el autor (Hall, 2016; Culp, 2016).
} 
la emergencia de otros estilos de vida tecnoconsumidores, sino nuevas formas técnicas de control urbano, vigilancia, segregación y otras estrategias biopolíticas para lidiar con el riesgo emanado de la exclusión y los cuerpos piratas; una dialéctica enloquecida entre luz y sombra, aterradora para el espíritu moderno que relaciona la oscuridad con las epidemias, el pánico urbano, la actividad criminal, el mito, lo no-racional, la superstición y los fantasmas, y que sirve para instaurar arquitecturas urbanas y dispositivos de vigilancia, transparencia y claridad (ver Sundaram, 2010, p. 19).

La constante "evaporación de fronteras entre tecnología y vida urbana... ha producido una ciudad kinética: una desorientación delirante de los sentidos" (Sundaram, 2010, p.7), que ha obligado a replantear los conceptos de sujeto, urbe, temporalidad y espacio, a la luz de este caos pirata. Sundaram coloca al fenómeno de la piratería en medio de esta desorientación de los sentidos, con paisajes de infinitas atracciones, donde imágenes, sonidos y objetos, se mueven rápidamente a través de la proliferación de redes, pequeñas tiendas (físicas y online), bazares, videoteatros, tianguis, y en el mano a mano, con amigos y conocidos (Cfr. Sundaram, 2010, p. 112). "La piratería escapa a las fronteras del espacio, redes particulares, forma, al antes y el después, al límite...la piratería por lo tanto, produce un plusvalor del código cultural, que fractura la superficie del espectáculo-media a través tácticas de dispersión" (Sundaram, 2010, p.112, 138). Emergen, entonces, todo tipo de estéticas, culturas y tecnoculturas piratas, y mecanismos de valorización y revalorización, conexión y extracción, ahora más invasivos y pervasivos.

Aunque no es objeto de este trabajo, es de gran importancia mencionar que es dentro de los estudios de las Modernidades Piratas donde emerge una crítica feroz a la pragmática modernoneoliberal que emplea conceptos como los de autenticidad, creatividad, originalidad, seguridad, futuridad, sociedad civil y ciudadanía, ahora como una vía de control y desempoderamiento. Es dentro de esta corriente de estudios culturales donde se esboza una potente crítica a las economías creativas y sus avatares de plataformas o informacionales, sobre todo de la mano de la filósofa china Laikwan Pang.

Este trabajo se adscribe a ese proyecto de estudios sobre Modernidades Piratas, y es una síntesis de un trabajo más amplio cuyo objetivo era pensar y conceptualizar, a través del desmontaje de la copia y sus trayectorias, y desde una mirada diagramática deleuzeana, los quiebres, movimientos y operaciones, suscitados en las denominadas piraterías y sus objetos, de donde pudimos despejar transformaciones y distorsiones experimentadas en la degradación, adecuación, extracción, desterritorialización y reterritorialización de los componentes semióticos de un mismo objeto en el acontecer de su copia. Y toda suerte de tensiones, desencuentros y reacomodos. Dada la relación de la piratería con el capitalismo contemporáneo, este estudio ofrece herramientas de análisis y claves de lectura para aquellos fenómenos que emergen de los desfases, conflictos y tensiones entre regímenes de control y vigilancia, locales y globales, y sujetos periféricos, dentro de un proyecto de modernidad que ha resucitado la mirada neoplatónica, devocional y religiosa en torno a lo original y las formas en las que son experimentadas las tecnologías. 


\section{Piratajes: reformulando la piratería}

El proceso que precede a los distintos tipos de piraterías, así como a las estrategias semióticas ${ }^{12}$ presentes dentro de los mismos -adecuación, extracción y degradación -, es el de pirataje, compuesto de varias fases: intercepción de los flujos de información, semióticos, materiales, económicos, etc., y la posterior extracción, replicación/inflexión o conversión (intervención) de sus códigos y propiedades con la finalidad de re-crear a los originales ${ }^{13}$ o algunos de sus atributos, derivando en diferentes objetos-copia. Este supuesto original es arbitrario y socialmente establecido, y funge como una suerte de representamen ${ }^{14}$ del que se parte para producir otros signos. Siendo predominante alguna de estas etapas (intercepción, extracción, replicación ${ }^{15}$ o intervención), dependiendo de la piratería estudiada.

El pirataje ejerce una suerte de inflexión, torcedura, curvatura o rizoma sobre el flujo ${ }^{16}$ que intercepta (sea de la naturaleza que sea), mapeando sus componentes, atributos, códigos o propiedades. Posteriormente duplica (y multiplica) al objeto del que parte o interviene, sin necesariamente aniquilarlo.

12 Les llamamos estrategias semióticas, a aquellos conjuntos operaciones dinámicas que preceden y posibilitan las distintas intervenciones sobre el sentido y la materialidad de los objetos, dentro los distintos fenómenos piratas.

${ }_{13}$ Supuestos o pretendidos originales, porque asumimos que aquello que es nombrado original, lo es por motivos de conveniencia social, comercial, política y de control, y que como tal, el original no existe. "El original", lo que es interpretado como cero o unidad de la que emergen signos continuadores y tributarios a un pretendido horizonte o haz originador, es realmente una tendencia inaugurada en el hábito y la convención, y no así una originalidad ontológica [pues es siempre perspectiva e inacabada (Foucault, 2012, p.228)]; es decir, lo que se concibe como punto de partida y "origen" se funda en "la tendencia a repetir cualquier acción que ha sido ejecutada antes" (Peirce, 2012 p.270), repetición que una vez cristalizada como hábito, suspende de la semiosis su cualidad demoniaca, es decir, la aparición de nuevos signos que caotizarían y pondrían en cuestión las estructuras y el poder o los poderes que sostienen al "original" convenido; así como a quienes detentan o se asignan de susodicho "original" el don y lugar privilegiado de su producción/creación (y su poder), estableciendo sistemas de interrelaciones y todo tipo de convenciones micropolíticas que "autorizan" y legitiman a unas tendencias (repeticiones) inauguradas en el hábito (y la convención) por sobre otras, haciendo posible la producción de "signos-continuadores". Es decir, se regula esta continuación. Se reduce a un código operativo de evocación, posesión, fijación, suprimiendo de la producción semiotizante los elementos que pudiesen desbordar de los cauces del control lo que se ha establecido como "original".

14 Para Peirce (1988), el representamen funge como el atado de condiciones de lectura e interpretación para un signo, una convención que condiciona, y posibilita su vez, a otros interpretantes y representamenes: "un primero que está en una tal genuina relación triádica a un segundo, llamado su objeto, que es capaz de determinar que un tercero, llamado su interpretante, asuma la misma relación triádica a su objeto en la que él se encuentra respecto del mismo objeto...un interpretante, con todo se transforma en un representamen tan pronto como es plenamente capaz de hacerlo" (p.144, 145).

${ }^{15}$ Con replicación acudimos a la genética para pensar, despejar y describir el dinamismo de las estructuras y procesos de producción, así como los distintos estatutos de la copia, presentes en las piraterías. Donde la replicación celular da copias idénticas, o bien, mutaciones que ponen en riesgo a la totalidad del organismo.

16 Un flujo, es una cadena significante "hecha de signos, pero estos signos no son en sí mismos significantes ... los signos aquí son de cualquier naturaleza, indiferentes a su suporte (¿o es el soporte el que les es indiferente?)" (Deleuze y Guattari, 1985, p. 44), indiferentes en tanto que cada corte es a su vez es la inseminación parcial de los códigos de las máquinas que remiten a otras máquinas. Cadenas de formación abierta y polívoca. Los flujos son cadenas significantes compuestas de los excedentes de la producción de producción, cuya materialidad no se reduce estrictamente a las mismas cosas, pueden existir flujos literarios, auditivos, visuales, gustativos, estéticos, ideológicos, etc. Los flujos son a su vez máquinas que cortan e iteran parcial o totalmente sus códigos, alterando tanto la "naturaleza" de los mismos, como lo que es "cortado" [proceso que puede ser infinito: "el registro recae sobre la producción, pero la propia producción de registro es producida por la producción de producción" Deleuze y Guattari: 1985, p.25)]. 
Figuna $\mathrm{n}^{\circ}$ 1. Pirataje de logotipos, ejemplo

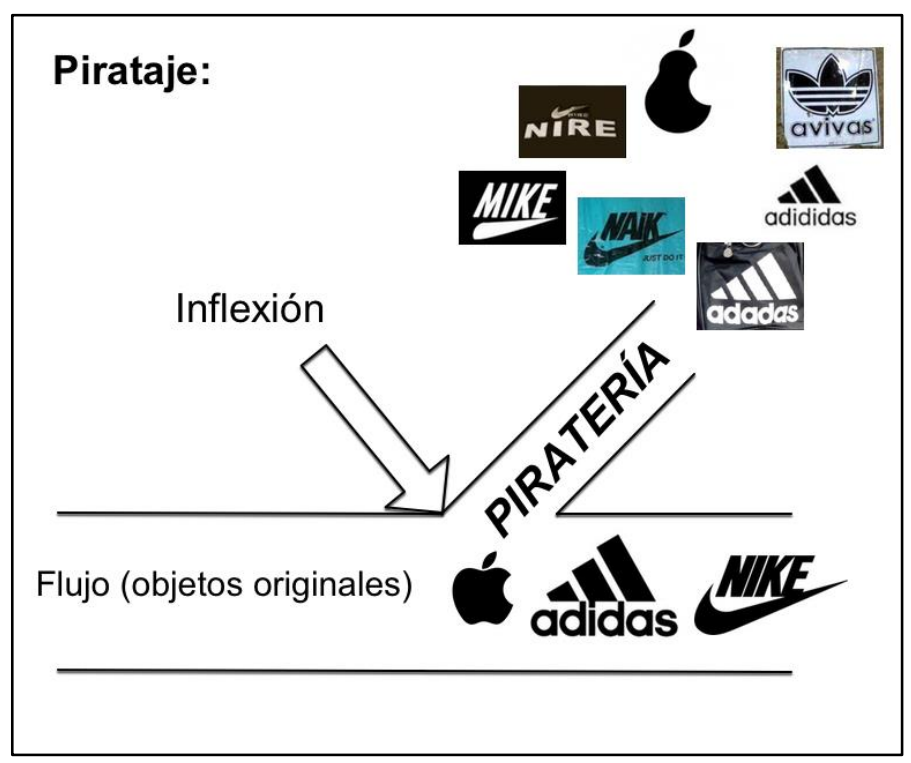

Fuente: elaboración propia

De ser el caso, lo descompone y sabotea. Inflexión maquinizante en tanto que, como lo expresan Deleuze y Guattari (1985), funge como un sistema de cortes (o interruptor de paso) en donde lo producido en el corte contiene residuos de los códigos que ha cortado, así como una serie de dimensiones y variables, las cuales pueden ser nuevamente cortadas, reproducidas e iteradas, o bien, intervenidas o modificadas. El corte a su vez es una máquina -con lógicas y atributos propios-, que produce a otros objetos-copia. El pirataje no se inflexiona de la misma manera dentro del ámbito literario, tecnológico, digital o de la producción objetual: debe darse cuenta del estatuto de la copia, imitación o replicación que comporta la piratería en cuestión, según el campo productivo que es objeto del acto de pirataje. Es el proceso de pirataje el que instaura a las piraterías (flujos replicados). Cada especie de piratería supone una máquina, atravesada por la lógica del pirataje, que la produce.

El fenómeno de la piratería no sólo atañe a la percepción y la edificación de imaginarios sociales legitimados y permitidos, sino también a formas auténticas de suspensión y rizomatización de las investiduras de sentido con las que fueron recubiertos los supuestos originales, potenciando a la copia y separándose del modelo dual del mimetismo "dependiente de una lógica binaria, para fenómenos de muy diferente naturaleza” (Deleuze y Guattari, 2009:39). Realizando a la copia por encima del modelo binario original-copia, de lo verdadero y lo falso, de lo uno y lo otro, acontece. Según Deleuze, este dinamismo implica:

Elevarse de lo condicionado a la condición para concebir la condición como simple posibilidad de lo condicionado... lo verdadero y lo falso permanecen indiferentes al principio que no determina la posibilidad del uno si no es dejándolo subsistir en su antigua relación con el otro... nos remitiremos de lo condicionado a la condición, pero también de la condición a lo condicionado (2011, p.46). 
La piratería es la expresión más tangible de la aniquilación no sólo de la dualidad original-copia, sino el signo del advenimiento de lo que Deleuze (1989) denominaría función-objetil $l^{7}$, y la proliferación de todo tipo de efectos con consecuencias materiales en distintas dimensiones. Asignando a la copia una condición de pura posibilidad, sin jerarquías ni diagramación posible ${ }^{18}$, o que al menos, los reconfigura incesantemente.

\section{Fases del proceso del pirataje}

El pirataje puede ser pensado como proceso, o conjunto de elementos y operaciones que cumplen con una función específica subyacente a los procesos de producción material e inmaterial, y a los distintos flujos que circulan en las denominadas sociedades de conocimiento. Es una máquina que engendra piraterías. Cada pirataje es un proceso singular compuesto de tres fases, de las cuales una puede estar más acentuada que otra, dependiendo la naturaleza de la copia y la piratería en cuestión ${ }^{19}$.

\subsection{Intercepción}

En un primer momento el pirataje, como proceso, intercepta los flujos semióticos, materiales e inmateriales, develando de los mismos sus regularidades o códigos motores: se trata de un mapeo indicial e icónico sobre aquello que se pretende copiar e integrar a la máquina de flujos piratas. Como expresa Deleuze, "los flujos reciben una cualidad propia en función del código" (2005, p.112); los flujos están siempre en relación con otros flujos, y en este orden, lo interceptado es interceptado con miras a su absorción y consecuente regulación, sin necesariamente dejar de relacionarlo y mezclarlo con otros códigos y flujos.

Esta fase revela que la piratería no siempre opera con la burda intención de realizar una copia de aquello sobre lo que se ha posado, sino que se trata de un fenómeno de reconocimiento y análisis de los territorios (nuevos o sin regulación), materias, sentidos, deseos, necesidades, en donde cumple con una función para el sistema que la sostiene, contrario a lo que se piensa de ella como un fenómeno maligno que interrumpe el mercado, el progreso, la creatividad universal y competencia democrática.

Esto supone, como antes exponíamos, la identificación de la composición y las cualidades constitutivas de los objetos (es decir, aquellos caracteres icónicos ${ }^{20}$ que acaparan la atención de los sujetos, permitiéndolos distinguir y diferenciar entre el original y los objetos alterados que derivan del mismo). Este aspecto del pirataje remite a la condición maquínica de la piratería y una función de taxonomización, identificación, absorción, ensayo y posterior regulación, para la máquina de máquinas que la sostiene, en este caso, un capitalismo global de flujos, reactivo, voraz y en constante mutación.

17 Lo que también Jean Baudrillard apuntaba en El intercambio simbólico y la muerte (1980) como la codificación/algoritmización del objeto (nuevos estatutos para el objeto y la experiencia con y del mismo). Una función-objetil puede ser entendida como una serie de sentidos o "atributos lógicos ideales" (Deleuze, 2011, p.53), que atados o diagramatizados, dan paso a proyectos de autenticidad, causas (cosas, propósitos, intenciones), promesas, información, usos programados, en otras palabras, efectos; estos efectos no son cuerpos, sino incorporales.

${ }_{18} \mathrm{La}$ copia se realiza en su nihilización, autonomización que ruptura con el modelo que la engendró en la contemplación.

${ }_{19}$ Puesto que bien pueden retomar desde sólo algunos elementos de los objetos o mercaderías focalizadas, hasta la totalidad de los mismos.

20 "Un icono es un signo que poseería la característica que lo hace significante, aun cuando su objeto no tuviera existencia alguna" (Peirce, 1988, p.158). 


\subsection{Replicación/inflexión}

La replicación, implica un conjunto de operaciones que hacen posible el corte, y/o la inflexión, de los flujos semióticos interceptados para la posterior ejecución de la copia: aquí opera la analogía que permite la esquematización de aquello que se va a cortar -o fue cortado-, es decir, la dinámica y los procesos de producción que han fundado una suerte de máquina o interruptor de paso (que corta y deja pasar) (Deleuze y Guattari, 1985, p. 42), en donde el corte no sólo imprime o deja rastros del código del flujo que corta sobre lo que deja pasar ("el producir está injertado en el producto" Deleuze y Guattari, 1985, p.15), sino que el hecho mismo de la fragmentación es lo que impone y condiciona la resustancialización/reterritorialización de lo cortado (fundando máquinas piratas de todos tipos). Esta fase es la de la copia y el proyecto (las posibilidades múltiples de lo inflexionado).

Por otro lado, la inflexión nos remite a la naturaleza particular del flujo o código que ha sido interceptado por la máquina pirata. Inflexión, significa, literalmente "torcedura", y es "inseparable de una variación infinita o de una curvatura infinitamente variable" (Deleuze, 1989, p.27); la inflexión altera, tuerce y provoca curvaturas en los flujos que intercepta, o bien, sobre los componentes, cualidades, códigos o propiedades del objeto -o flujo significante- interceptado, al que duplica, copia o multiplica, sin necesariamente aniquilarlo.

La inflexión favorece $N$ posibilidades de plasmar, en otro objeto o flujo, las propiedades semióticas del supuesto original interceptado, que permiten identificarlo a pesar de su recomposición: como lo expresa Bernard Cache (1995), la inflexión implica un momento de abstracción que proyecta el conjunto de las posibilidades imaginativas de lo abstraído: "en este sentido, inflexión representa la totalidad de posibilidades, así como la apertura, receptividad, o anticipación" (Cache, 1995, p.16). Por ello, es necesario tener en consideración que para cada piratería existe un pirataje específico ${ }^{21}$ : la inflexión obedece a la naturaleza relacional del flujo interceptado, y debe darse cuenta pues, del estatuto de copia, imitación, simulacro o replicación que el tipo de piratería estudiada comporte. Debe estar presente la cuestión por el ¿qué es lo que, contextualizada y relativamente, se está pirateando?

\subsection{Intervención}

El tercer momento, intervención, implica la manipulación material o inmaterial (esquemática) de las propiedades del objeto semiótico interceptado para ser fijadas en un objeto otro, o copia. Es posterior al proceso de replicación e inflexión (las cualidades, códigos y flujos del objeto intervenido identificadas y mapeadas), y su ejecución puede ser parcial o total. Parcial: la evocación, dilución o degradación de las propiedades del objeto intervenido, mediante diversas estratagemas, tácticas y dispositivos semióticos ${ }^{22}$ realizados en los objetos-copia; y total: la reproducción de una copia

\footnotetext{
${ }^{21}$ Lo que se ve inflexionado dentro del ámbito literario (que va del plagio a la producción de copias ilegales de los manuscritos o de sus avatares digitales) no es igual dentro del ámbito tecnológico-digital (el despliegue de diversas estrategias para facilitar el acceso a los objetos culturales digitales o a los códigos que posibiliten la modificación e intervención de los hardware o software), dentro del ámbito cultural-biológico/orgánico (como el reaprovechamiento de conocimientos o saberes populares y su traducción a un lenguaje que permita establecer su patente, despojo y posterior explotación), dentro de la producción objetual (la producción técnica de copias o similares, el despliegue de estrategias de sustracción de objetos-originales para ser puestos a la venta en lugares no contemplados por sus fabricantes, la apropiación de las cualidades técnicas/estéticas de las marcas, etc.), ad infinitum.

${ }^{22}$ Un conjunto de elementos y disposiciones que buscan intervenir un sentido, ambiente (mood), afecto, o detonar un efecto específico.
} 
exacta a través de sofisticados mecanismos técnicos ${ }^{23}$. La intervención opera sobre los objetos o los flujos. No sólo está presente el factor de la ganancia (trátese del sabotaje, el reaprovechamiento o la vendimia de la mercadería robada o pirateada) sino también el político y cultural (quiénes y para qué usan y producen piratería) ${ }^{24}$.

La intervención puede provocar varios efectos posibles: entre ellos la fruición que reivindica a la copia frente a un original, el sabotaje - que queda de manifiesto en el desprestigio a la instancia intervenida, la anulación simbólica del lujo del acceso/compra legal y la supuesta exclusividad del objeto-; efectos calculados o accidentales en estrecha relación con la creación/destrucción y la politización (o radicalización) de la piratería $\left(\right.$ pyros $^{25}$ ).

Podría decirse que el primer momento [(a) Intercepción], maquinal, da cuenta de las relaciones que posibilitarían la construcción analítica de la máquina pirata que ha dado paso al objeto-copia que está siendo estudiado y analizado, su relación con otras máquinas piratas y con la máquina de máquinas capitalista; mientras que el segundo momento [(b) inflexión/replicación], da cuenta de las $N$ formas de extracción que a su vez asignan singularidad a cada proceso de pirataje develando la trama maquinaria de cada corte o inflexión subyacentes en la copia. Y el último [(c) intervención], la realización material de los dos anteriores que descubre de lo copiado las condiciones del entorno cultural y material que lo originaron, además de la sofisticación (o ausencia de ésta) del artefacto o dispositivo radicado en el objeto-copia que está interceptando y extrayendo las propiedades legitimadas y canonizadas comercial, política y socialmente.

\section{Estrategias interventivas}

Lo que proponemos es pensar el pirataje como un proceso que atraviesa las piraterías y cuya descomposición a manos del analista ofrecería posibilidades de estudio sobre el contexto, las dinámicas de flujos, producción y modalidades en las que son distribuidos los conocimientos, mercancías culturales, los lugares de elocución y recepción del sentido, así como las funcionesautor y las funciones-lector presentes ${ }^{26}$, y las tensiones que esto implique.

El estudio de las piraterías, su regulación y la producción cultural descubre las dinámicas hegemónicas de sometimiento, explotación, extracción y saqueo cultural. Es importante entender

23 Significaría conocer los procesos, mecanismos y técnicas que los produjeron: "el montaje y la codificación exigen efectivamente que el receptor desarme y descodifique el mismo proceso" (Baudrillard, 1980, p.74).

${ }^{24}$ La piratería es usada como canal para posicionar y dar a conocer marcas, objetos-mercaderías, etc., antes de que arriben las versiones auténticas: la piratería "introduce el producto [ideas, discursos, deseos] en un nuevo mercado antes de que la versión auténtica arribe. Los consumidores que carecen de poder adquisitivo, son también entrenados para desear marcas. La piratería llena fácilmente esta brecha entre el deseo de consumo y el poder de adquisición [real], aunque esto permite a los piratas devorar la primera oleada de lucro [y (re)aprovechar y extractivizar todas las estrategias de marketing y proyección en media, antes de que arribe el merchandising 'original', parasitando sus momentos más altos]" (Laikwan Pang, 2006, P.96, los corchetes son nuestros). En el contexto mexicano podríamos mencionar el caso de la piratería de ánime, música, series y películas, encargada de diseminar y dar a conocer un sin fin de objetos-comunicativos, a pesar no haber sido transmitidos en canales de radio y televisión abierta o de paga. Diseminación que posteriormente capitalizan las corporaciones (y sus tiendas virtuales), vendiendo todo tipo de objetos "de colección" a precios sumamente prohibitivos, explotando las pasiones de algunos consumidores piratas.

${ }^{25}$ La piratería guarda en su núcleo la impronta de la gesta del sistema económico depredatorio vigente: la fuerza del saqueo, el fuego y el despojo, así como la capacidad de alterar o copiar aquello que envuelve (trátese de lo que sea). Pyros (fuego) es una de las posibles raíces del término piratería, bastante revelador.

26 Función-autor: unidades de acontecimiento, lugares (socialmente construidos) de autoridad o posiciones de enunciación privilegiadas e investidas del mito de la creatividad/originalidad (platónica) (Foucault, 2010). Funciónlector: aquellas destinadas únicamente al consumo de estos materiales sin necesariamente haber sido partícipes en el proceso creativo de su producción -o que al menos no recibieron retribución de ningún tipo, y fueron despojados de su poder autoral-. Consumidores necesarios para sostener los privilegios de la función-autor. 
el contexto globalizado, y tener presentes tanto las éticas de negocios y demás aspectos del derecho sobre la propiedad intelectual, sin embargo, nosotros subrayamos la necesidad de entender las dinámicas de flujos que preceden a los objetos y fenómenos piratas, considerando los aportes críticos de los estudios de las culturas de la copia ${ }^{27}$, el mapeo y posterior deconstrucción de sus objetos y la cultura material. La piratería es útil al capitalismo que la sostiene, genera valor y se alimenta de las zonas grises que la misma engendra, revolucionando el sistema.

Partiendo de la descomposición de los objetos-piratas se pretende descifrar el proceso de pirataje que los originó, e identificar y estudiar algunas de sus estrategias semióticas: distorsión, degradación y adecuación. Estas estrategias pueden alterar el objeto o flujo interceptado, o bien, aniquilar al objeto y redireccionar los flujos. Estas categorías pueden ser interventivas o nointerventivas, es decir, involucran técnicas que han modificado o transformado por completo los objetos "originales" copiados, o no, y pueden llegar a crear nuevos objetos, develando aspectos interesantes de sus dinámicas de flujos. Gran parte de estas categorías pueden estar presentes en distintos objetos-copia, dejando ver que estos objetos no son "puros". Habremos de recordar que la piratería que parasita los flujos, lucra con ellos sin precisamente retribuir ganancia alguna a la instancia interceptada, pero que dentro de la gama de efectos posibles, además del lucro, está latente la posibilidad de mermar las condiciones objetivas que hicieron posible el original (sabotaje), y entre otros más, la absorción y normalización de las novedades y procesos de producción informales y/o periféricas a sus maquinarias. ${ }^{28}$

Estas estrategias atravesadas por los tres momentos del proceso de pirataje (intercepción, replicación/ inflexión, e intervención), están presentes en varios fenómenos y objetos piratas:

\subsection{Estrategias de degradación}

Introducción de elementos extraños o ajenos al objeto original, o la respectiva omisión de algunos elementos (presentes en el original), transformando la calidad del mismo, o bien, adulterando o mutando sus propiedades. En la pretensión de hacerse pasar por el original, los elementos o propiedades del original pueden ser transferidos y re-ensamblados en la copia con total desorden (intercambiando y superponiendo las propiedades del mismo), transformando, mejorando y/o degradando (accidental o conscientemente) su composición o esquema y sin precisamente dejar de connotarlo.

Estas estrategias distorsionan, ralentizan o aceleran, adulteran, estiran o contraen, corroen y descomponen la materialidad del objeto, en donde la copia, como expresa Baudrillard "puede aparecer de esta forma como la parodia del original, su versión irónica y grotesca” (Baudrillard,

\footnotetext{
${ }^{27}$ Estudios que van de la presencia, conflictos y estatutos de la copia en el arte y la museografía, hasta sus funciones no contempladas dentro algunas actividades de la cultura popular, como el fanzine, el scanlation (escaneado y traducción de mangas) y el fotocopiado de libros, y los espacios de su tránsito, comercialización, producción, distribución y consumo, y las estéticas que emanan de las dichas culturas. Etc. (Ver Schwartz 1996; Melot, 2010; Boon, 2010; Bosker, 2013; Borschke, 2017; Radnóti, 1999, Lins Ribeiro, 2018; Baudrillard, 2012; Ruiz, 2020)

28 Las condiciones técnicas de reproducción hicieron posible aminorar las diferencias entre originales y copias (algunas veces mejorando y adaptando el original a contextos no contemplados por la instancia original); las marcas compensaron las perdidas ocasionadas por las sustracciones hormiga reintegrando a su stock esos productos modificados y adaptados a las necesidades y deseos del mercado, uno de los ejemplos clásicos son las bolsas de Louis Vuitton, cuya presentación oficial fue intervenida para adaptarla a las necesidades, rutinas y gusto popular de las personas, para confeccionar versiones piratas en otros colores, bolsas internas adicionales y materiales mucho más resistentes a la lluvia, que pudieran venderse con mayor facilidad.
} 
2000, p.44).

Las estrategias de degradación, por otro lado, no significan la aniquilación total de los elementos que son inflexionados por el pirataje (estilo, materiales, logos, función), por el contrario, se trata de distorsionarlos, alterar su velocidad y su tamaño (con finalidades varias, como la transmisión, la pronta circulación, el acceso, etc.), estirarlos, contraerlos mediante la descomposición/recomposición que si bien puede derivar en su corrosión, esto no es necesariamente aniquilar de tajo lo transmitido. Pues precisamente, la degradación es una disgregación de modos de ser de un acontecimiento-fantasma mismo: "con el riesgo de que el acontecimiento representado en el fantasma sea captado como otro individuo, o más bien como, una serie de otros individuos por los que pasa...disuelto" (Deleuze, 2011, p.251). Lo que es evocado permanece allí, ominosamente.

Aunque esta estrategia puede ser empleada a distintos niveles para un mismo objeto-copia, sin importar cuál sea, desde un producto comestible, logo, diseño, u objeto de moda (bolsas, prendas, calzado, tecnología), podemos encontrar algunos ejemplos de estas estrategias en la estructura de las películas piratas y los lags que derivan de su circulación masiva: se interrumpen, se mezclan (o el final, u otra escena significativa se desfragmenta para colarse en la estructura visual de la película, rompiendo la narrativa), salta, se pausan, se callan, obligan al espectador a involucrarse, transformando su experiencia. Cómo apuntaba Sundaram (2009), estas estrategias dan pauta a formas inusitadas para experimentar la temporalidad, materialidad, exclusividad, y son al mismo tiempo fuente de ambigüedad cultural masiva en el régimen de autoría, autenticidad y originalidad conferido a las cosas. El objeto visual pirata brinda la posibilidad de distanciarse tanto de los espacios, la tecnología y sus usos impuestos como vía canónica y oficial, como del propio contenido, a través de todos esos colapsos, empalmamientos, repeticiones, distorsiones y errores. Tal efecto le recuerda a la audiencia la "no-presencia" (tanto del objeto en cuestión, como de la suya dentro de dicho objeto) y su posición no-participatoria dentro del acontecimiento programado de la moda, o al menos, su participación desde la "incompletitud" (Ver Pang, 2006, p.94).

Estas estrategias de degradación pueden ser administradas para brindarle velocidad, y fluidez, a los objetos intervenidos, como lo señala Hito Steyerl (2014) en su estudio sobre las imágenes pobres: se pierde materia pero se gana velocidad; la compresión es a su vez desmaterialización y rematerialización constante, y devela una forma de valor definida por la velocidad, la intensidad y la difusión (p.43). Se extraen los datos para ponerlos en todo tipo de repositorios, y este constante hacer, degrada, corta, altera o adultera la imagen o su composición.

\subsection{Estrategias de adecuación}

Ensamblan, con elementos de menor calidad, un similar al original. Los objetos son trasladados a un formato o soporte similar, donde la narración y códigos del objeto no son aniquilados o alterados, sino adecuados $^{29}$. Se privilegia la búsqueda de la equivalencia a través de procedimientos técnicos de imitación, con la intención de reproducir las cualidades indíciales e icónicas de un objeto, poniendo especial atención a los detalles de su composición: en otras palabras, se trata de una reducción de las diferencias entre el objeto copiado y el objeto

\footnotetext{
${ }^{29}$ Pueden también obedecer a necesidades de todo tipo, ajustándose a lo que el consumidor busca, sea ideológico o material, para expresar algo o para satisfacer una necesidad real de primer orden.
} 
reproducido para ofrecer una copia exacta o inexacta ${ }^{30}$.

Deslizamientos dentro de la composición de la copia o falsificación, a la que buscan hacerla pasar por otro (el original), el efecto buscado es la asociación de sus rasgos o propiedades más distintivas, difuminando las diferencias matizadas por el error y la imperfección ${ }^{31}$. La estrategia de adecuación (exitosa o no) representa, en sí misma, una acción transformadora que altera, enloquece las cualidades y cantidades de los elementos semióticos presentes en la composición de aquello que pretende ser adecuado, deslizándolos, evocándolos, con juegos y regates, imitando sus trayectorias y fabricando la atmósfera que los rodea. Es también una estrategia (modular) de recreación: adjudica por contigüidad un elemento semiótico que detona el efecto de la familiaridad propio de un signo que ya ha sido posicionado mediante estrategias de mercadotecnia o gestión cultural corporativista.

Estas estrategias pueden reproducir exactamente los procedimientos técnicos o artesanales de los objetos sin necesariamente igualar las materialidades o la supuesta calidad de las mismas ${ }^{32}$, detonan la alusión, semantizan e invisten un objeto por contigüidad o asociación (como aquellos objetos que se exhiben en los tendederos del comercio informal y los tianguis), persiguen la imitación. Es decir, existen gracias a los originales y no buscan suplantarlos sino reaprovecharlos o extractivizarlos.

Un ejemplo icónico de estas estrategias de adecuación, ha sido la proliferación de tiendas Apple piratas alrededor del mundo, donde no sólo los objetos y los espacios (sus proporciones, cualidades, funciones y presentaciones) lograban evocar la atmósfera, aura y mística de la marca en cuestión, sino que los compradores y fans de Apple se relacionaban y construían sus vínculos como si en realidad se tratara de los objetos y espacios oficiales. Fan Yang (2016) estudió este fenómeno en China. Él apunta que una vez lograda la creación de unas interacciones entre las formas específicas de circulación, performatividades, resonancias y modulaciones entre dispositivos semióticos generadores de sentido, así como la constitución de unas comunidades interpretativas alrededor de estas relaciones y dispositivos (p.16), China dio el siguiente paso y sustituyó a las marcas interceptadas por marcas locales (sin que esto significara precisamente el fin de las piraterías tecnológicas, sino su evolución), un complejo pirataje que abrió paso al moderno objeto shan₹hai: artefactos con vida y aura propia (aunque no por ello desprendida de aquellos objetos de los ha partido para constituirse/dividuarse como tal), ad hoc a los turbulentos flujos piratas, tan sencillos e inexactos como complejos y sofisticados, que poco a poco empezarían inundar los centros comerciales, bazares y calles del planeta, así como a construir su encanto y particular soft power. Objetos con una capacidad constante de adecuación y recreación, dispersión y penetración (Ruiz, 2020; Yang, 2016).

\subsection{Estrategias de extracción}

Es quizá la faceta más compleja y significativa de la dimensión semiótica de las piraterías. Estas estrategias pueden ser definidas como dinámicas de usufructo y capitalización de las distintas propiedades y recursos semióticos endémicos de contextos culturales específicos y sus objetos, que las modalidades de la industria y los sistemas culturales hegemónicos utilizan para impulsar

\footnotetext{
${ }^{30}$ Ejemplos de copias inexactas: Joyería, perfumes, imágenes (dinero), calzado, ropa, alcohol.

31 Ejem: visible en los logos, empaques y diseños de las imitaciones. También puede ocurrir en la composición estética: música (Sampling/Scratch), fotografía o cine.

${ }^{32}$ Ejem. litografías, películas, música, libros, videojuegos, “clones”.
} 
su productividad (o renovar su stock con propósitos de sujeción y expansión) ${ }^{33}$. Si bien, no es del todo posible hablar de un original, en cambio, sí es posible hablar de elementos y propiedades sígnicas, producto de la semiotización del entorno realizada por los sujetos que lo habitan: elementos y propiedades que no son puros, pero que con el paso del tiempo fundan el entorno cultural, asignando a los sujetos formas idiosincráticas y signos particulares (mas no inmutables) para referir su mundo.

La extracción, consiste en la separación de las ideas, códigos y propiedades semióticas que asignan cierta singularidad a un objeto (material o inmaterial), para posteriormente ser colocadas en la composición o los códigos de otro objeto. El proceso de pirataje, en este caso, decodifica y extrae la información del objeto pirateado, y reterritorializa las cualidades o propiedades de dicho objeto. Esta dinámica de absorción capitaliza la antigüedad, circulación, sentidos, relaciones afectivas, trabajo invertido o singularidad de dichos códigos y propiedades, haciéndolas pasar como una creación propia y adjudicándose el derecho a su usufructo (en todas sus dimensiones $)^{34}$. Esta categoría operatoria está presente en el fenómeno del semioextractivismo y semioexplotación (facetas de una suerte de saqueo cultural) ) $^{35}$ y en el plagio: "el libre uso de creaciones y estilos del tercer mundo por artistas más privilegiados (y mejor pagados)” (Lethem, 2009, p.34, el paréntesis es nuestro).

En las estrategias de extracción pueden suscribirse algunas operaciones de sustracción ${ }^{36}$ (una modalidad de intervención) parcial o total de los elementos de aquello que es objeto de un pirataje. La desterritorialización y la reterritorialización de los códigos y flujos, operaciones latentes también en las dinámicas de semioexplotación y semioextractivismo, corporativo o de sistema cultural a sistema cultural, sentando hegemonías de todos tipos. Operaciones que involucran aspectos como el poder, la explotación, el sometimiento y la dominación codificada, o

33 Donde ya no interesa lo producido en la cadena, sino el valor generado en el exterior, es decir, en su circulación, apropiación y reapropiación: lecturas, interpretaciones, adecuaciones, adaptaciones, modificaciones, implementaciones nuevas, mejoras, afectos, etc.

34 Ejemplos: fórmulas herbolarias patentadas y capitalizadas por las farmacéuticas; la apropiación que hace la industria hegemónica hollywoodense de las estéticas, historias, técnicas y estilos de filmación realizadas por cinemas en posiciones subalternizadas; y el trabajo no remunerado y afectivo del fandom, entre otros.

35 Con semioextractivismo y semioexplotación nos referimos a procesos de subsunción y despojo de carácter semiótico. Haciendo un símil con la noción antropogeográfica de extractivismo, postulamos y replanteamos el concepto para dar cuenta de una serie procesos de refuncionalización y revalorización cuya ganancia no va para aquellos sujetos que originaron o "crearon" las materias en cuestión, sino para una instancia tercera que las parasita y capitaliza a través de distintos métodos y artilugios, que contemplan lo legal y lo ilegal.

36 Por sustracción, Gilles Deleuze (2011), plantea un proceso en el que, después de un mapeo y diagramatización de las cualidades constitutivas de un objeto primero, y las potencialidades de las mismas en relación a algo, es posible la selección, valorización y reconducción de algunas de éstas, a otro lugar, artefacto u repositorio, para ser reaprovechadas, re-valorizadas, y empleadas para producir o forjar otros objetos a partir de las mismas (que no necesariamente implican la aniquilación del primero, ni su cancelación, sino el empleo modulado y parasitario de sus cualidades y componentes). En este sentido, entendemos que esta operación puede ser parcial o total, en tanto que apunta a la extractivización y posterior reaprovechamiento y capitalización de las cualidades y materias semióticas de un objeto específico (literario, audiovisual, afectivo, tecnológico, gastronómico, cultural, del orden del saber popular o de la producción académica, etc.), que no implican la aniquilación de ese objeto, sino su parasitación en vísperas de generar valor, ganancias, estatus, información o conocimientos que posteriormente puedan ser empleados en sistemas especulativos con el fin de obtener ventaja (P.ej. el uso de un sistema de ideas ajeno haciéndolo pasar como novedad o descubrimiento propio; la apropiación de rituales o cosmovisiones de culturas ajenas para producir merchadising; la apropiación hegemónica de las culturas contestatarias o las tendencias musicales que nacen de la creatividad de usuarios periféricos de la internet, para su posterior explotación en los circuitos mainstream; el uso de las economías colaborativas y los fandoms como laboratorio de upgrades, ideas y nuevos contenidos, donde todo ese trabajo aficionado es reaprovechado por las agencias de marketing y equipos creativos, etc.); donde sus poseedores o creadores, o son invisibilizados, o son sustituidos por la instancia parasitaria. En los extremos de esta operación se encuentran el plagio, robo o despojo. 
el despojo.

Estas operaciones obedecen a una forma más agresiva de pirataje, pues hay de por medio no sólo el usufructo, sino, antedicho, la explotación, el ilegalismo, el timo y la sustracción. Sus avatares van desde el plagio, hasta el necrocomercio (tráfico de drogas, armas, pornografía de todos tipos, órganos y prostitución); podríamos adscribir también a las intercepciones (mano armada) de camiones o vehículos oficiales de transporte de mercancías con la intención de sustraer y cambiar el rumbo de las mismas, el establecimiento de espacios de acumulación y redistribución de bienes piratas (bodegas), operaciones de tráfico hormiga, y las distintas operaciones de compra de mercancías en el extranjero (a menor precio y minando a quienes deciden $-\mathrm{o}$ se ven obligados- a sujetarse a los regímenes hacendarios) con la finalidad de burlar algunos impuestos en las aduanas y posteriormente revenderlos en las denominadas fayucas, plazas de la tecnología, tianguis, “frikiplazas”, etc.- (Alarcón, 2008).

\section{Efectos posibles: sabotaje, fruición y engaño}

Se podría hablar de tres efectos posibles derivados de estas estrategias: sabotaje, fruición y engaño. Sabotaje: efectos accidentales o esperados, suscitados cuando el proceso de pirataje es llevado a un extremo, capaz de efectuarse en diferentes órdenes o dimensiones de un mismo objeto/artefacto intervenido o sustraído, incidiendo en la imagen, prestigio, materialidad o atmósfera que pretende instaurar, generando sentidos y contrasentidos, ironías o sarcasmos (que distan de las que se tenían proyectadas para ellos). Como efecto, el sabotaje descubre aspectos no sólo organizativos, sino de conceptualización y proyección estética sobre aquello que planea intervenir "el abanico de todos estos escenarios de disuasión" (Baudrillard, 2012). Cuando es accidental el sabotaje distorsiona la carga significativa, reputación e imagen de aquello que ha sido pirateado. Y como proyecto, con todo el pyros potenciado e inflexionado (por la impronta del simulacro en él), es capaz de destruir lo copiado y la producción seriada, en distintos niveles ${ }^{37}$ :

el simulacro no es una copia degradada; oculta una potencia positiva que niega el original, la copia, el modelo, y la reproducción. De las series divergentes, al menos, interiorizadas en simulacro, ninguna puede ser asignada como original, ninguna como copia (Deleuze, 2011, p.305).

Como efecto, la fruición del objeto pirata hace posible resignificar el discurso que mantiene intacto el orden de la hegemonía autoral, canónica y validada por el mercado, para apropiarse, transformar e iterar nuevos usos y propiedades para esos objetos. La fruición es potenciada en el deseo de los sujetos, en donde si la aparente falsedad del objeto pirata, como así lo expresara Peirce, "no puede nunca llegar a descubrirse, y cuyo error por tanto es absolutamente incognizable" (1988, p. 119) este objeto deja de contener error alguno, y la distinción entre éste y

\footnotetext{
${ }^{37}$ Calibra de la copia la corrupción (una degradación intencionada), el aumento (preparado para desbordar algo), o la disminución (hasta la vulnerabilidad o la anulación), para destronar un aspecto, o enfatizarlo con cierto détournement (Debord, 1959). La liberación de objetos toda vez que los mecanismos de regulación, control y vigilancia han quedado anulados, dañados o destruidos (como cuando se captura en fotogramas, hoja por hoja, un ebook para su posterior transformación a un formato PDF, su impresión y distribución; o cuando se ha logrado hackear una consola de videojuego para que pueda leer emuladores; o se extrae el $\mathrm{R} A W$ de una película previa destrucción del candado, etc.). También está presente cuando los prototipos de algún producto en el que ya han invertido bastante dinero en publicidad con la finalidad de generar expectativa, queda arruinada por filtraciones (parciales o totales) de sus detalles y sus limitaciones (alterando el curso de la especulación o probable inversión/beneficio del mecenazgo).
} 
el original, queda suspendida en tanto no existen condiciones lógicas para su distinción. Por otro lado, de ser consciente el individuo de que el objeto en cuestión se trata de una copia, el objeto se ve potenciado en la lúdica y su deseo, permitiendo ejercer una distinción agresiva entre el objeto-copia y el objeto-original, derivando en un nuevo objeto que a pesar de carecer del guiño y la aceptación legal y consensuada, ha adquirido una función personalizada e individualizante para el sujeto que lo ostenta.

El engaño, como efecto, se encuentra entre el sabotaje y la fruición, y funge como un velo ilusorio sobre el artefacto pirata producido. Existe únicamente después de haber sido descubierto, dejando entrever distintas estrategias arqueológicas de rastreo sobre aquellas formas y mecanismos mediante las cuales fue maquinado. Bien para aparentar ser o tener (o poseer una propiedad o cualidad específica), el engaño deja ver del pirataje, entre otras cosas, su capacidad para sostener y generar ilusiones que inciden materialmente en el contexto y sobre los sujetos.

Figura n 2. Lógica del pirataje, estrategias interventivas, efectos posibles.

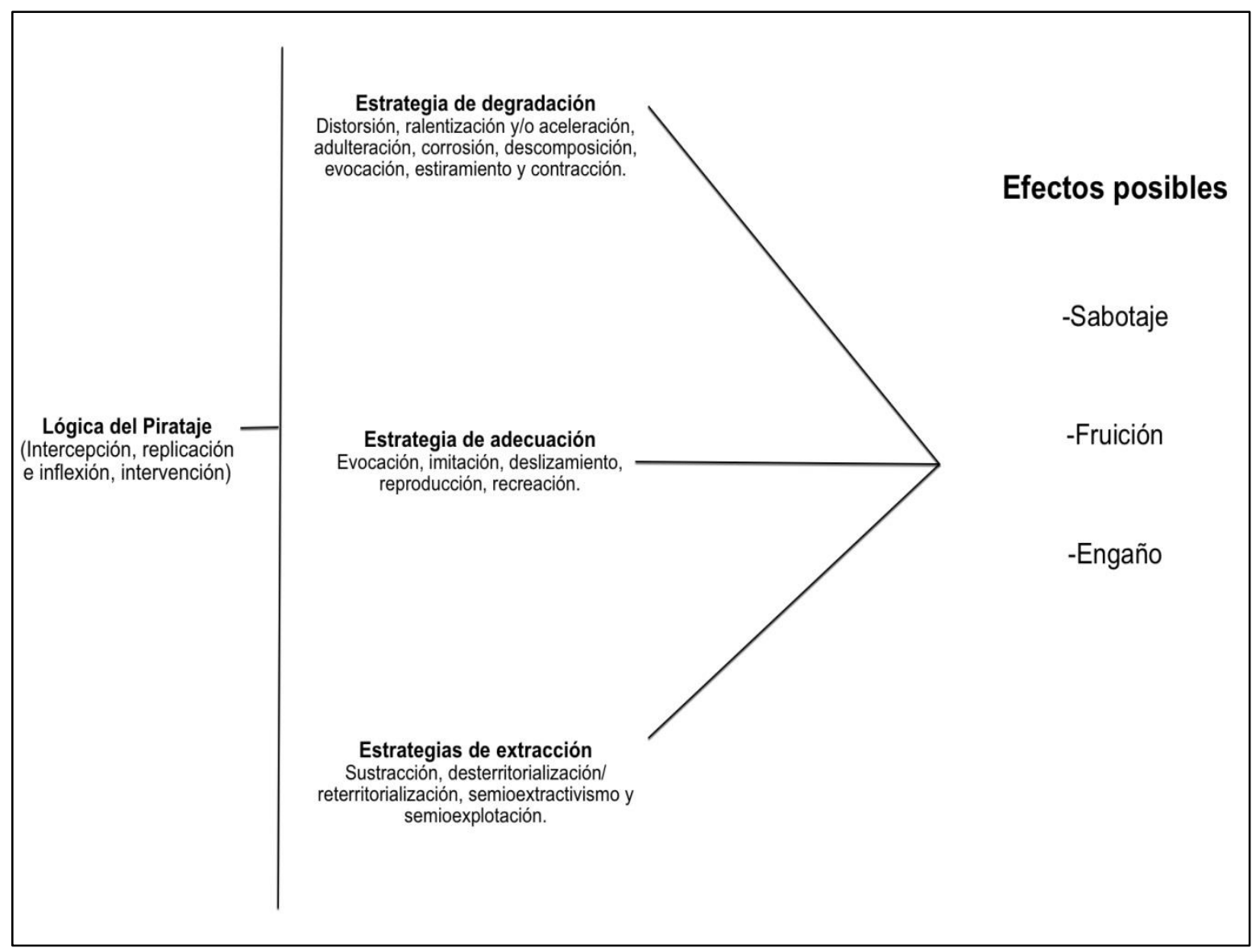

Fuente: elaboración propia

\section{Conclusión: nuevos horizontes del pirataje}

Además de una aproximación al fenómeno de los piraterías, nuestra intención es aportar una suerte de herramienta abierta para abordar distintos fenómenos piratas (a nivel sociocultural, semiótico y estético), así como aquellos piratajes que, en el horizonte, parece que tienen procesos más sofisticados de intercepción y extracción, como los extractivismos semióticos (culturales, afectivos, cognitivos, informacionales, etc.). 
Estos piratajes extractivistas corresponden a una relación de poder ejercida por instancias que no sólo han encontrado la manera de traducir dichos materiales semióticos (como el lenguaje, las actividades ociosas, los afectos, los pensamientos, etc.) a datos en cuyos entrecruzamientos son capaces de generar valor, ventajas o ganancias, sino de despojarlos de forma imperceptible y aparentemente inocua, a través de la disposición de entornos tecnologizados, vigilados e hiperconectados. Infraestructuras de tamaño planetario y ecologías extractivistas que condicionan las mecánicas del don, y obedecen a un capitalismo en busca de nuevos recursos para su explotación, en donde la capacidad de semiotización (es decir, de interpretación y absorción) constante de los sujetos juega un proceso importante para la producción de actualizaciones, adaptaciones o novedades. Los piratajes pueden abrir camino a un capitalismo, aparentemente, sin restricciones, y que acumula rizomas antes que anularlos. Un capitalismo que guarda, connive, y coexiste con las piraterías.

\section{Referencias}

Alarcón, S. (2008). El tianguis Global. Universidad Iberoamericana.

Alba Vega, C., G. Lins Ribeiro, G. Mathew (2015). La globalización desde abajo. La otra economía Mundial. Fondo de Cultura Económica/ Colmex.

Baudrillard, J. (2000). El intercambio imposible. Cátedra.

Baudrillard, J. (1980). El intercambio simbólico y la muerte. Monte Ávila Editores.

Baudrillard, J. (2012). Cultura y simulacro. Kairós.

Boon, M. (2010). In praise of copy. Harvard University Press.

Bosker, B. (2013). Original copies. Architectural mimicry in contemporary China. Hong Kong University Press.

Borshke, M. (2017). This is not a Remix. Bloomsbury.

Cache, B. (1995). Earth moves. The furnishing of territories. MIT.

Culp, A. (2016). Dark Deleure. MIT.

Deleuze, G. (1989). Elpliegue. Paidós.

Deleuze, G. (2011). Lógica del sentido. Paidós.

Deleuze, G. (2009). Diferencia y repetición. Amorrortu.

Deleuze, G. y F. Guattari (1985). El antiedipo. Capitalismo y esquizofrenia. Paidós.

Fish, A. (2017). Technoliberalism and the end of participatory culture in the United States. Palgrave Mcmillan.

Foucault, M. (2010). ¿Qué es un autor?. El cuenco de plata.

Foucault, M. (2012). Lecciones sobre la voluntad de saber. FCE.

GNU (2018) ¿Qué es el copyright? Disponible: https://www.gnu.org/licenses/licenses.es.html Hall, G. (2016). Pirate philosophy. MIT.

Hemmungs Wirtén, E. (2006). Out of sight and out of mind. On the cultural hegemony of intellectual property (critique). Cultural Studies Vol. 20, Nos 2-3 Marzo/Mayo 2006, 282-291. https://doi.org/10.1080/09502380500524145

Johns, N. (2015). The social logics of sharing, The comunication review, 16:3, 113-131. https://doi.org/10.1080/10714421.2013.807119

Karaganis, J. (2012). Piratería de medios en las economías emergentes. Columbia University. http://piracy.ssrc.org 
Larkin, B. (2013). The politics and poetics of infraestructure. The Annual Review of Anthropology, 42, 27-43. https://doi.org/10.1146/annurev-anthro-092412-155522

Lessig, L. (2004). Free culture. How big media use technology and the law lock down culture and control creativity. Penguin Press.

Liang, L. (2009). Piracy, creativity and infraestructure: rethinking acess to culture. SSRN http://dx.doi.org/10.2139/ssrn.1436229

Lins Ribeiro, G. (2018). Otras globalizaciones. Gedisa/Universidad Autónoma Metropolitana.

Lobato, R. (2014). The paradoxes of piracy. En Lars Eckstein y Anja Schwarz (2014). Postcolonial Piracy. Media Distribution and Cultural Production in the Global South. Bloomsbury Publishing.

Johns, A. (2009). Piracy. The intelectual property wars from Gutenberg to Gates. University of Chicago.

Melot, M. (2010). Breve bistoria de la imagen. Siruela.

Neves, J. (2020). Underglobalization. Beijing's media urbanism and the chimera of legitimacy. Duke.

Pang, L. (2006). Cultural control and globalization in Asia. Routledge Media.

Pang, L. (2012). Creativity and its discontents. China's industries and intellectual property rights offenses. Duke University Press.

Peirce, Ch. S. (1988). El hombre, un signo. Editorial Crítica.

Peirce, Ch. S. (2012). Obra Filosófica Reunida.Vol.1, FCE.

Philip, K. (2012). ¿'Tecnologías para pobres o pobres tecnologías? Poscolonialismo, desarrollo y tecnología en la India. Nómadas, 36, 91-108. http://www.scielo.org.co/scielo.php?script=sci_arttext\&pid=S0121-75502012000100007

Philip, K. (2008). ¿Qué es la autoría tecnológica? La piratería y la propiedad intelectual. Nómadas, 28, 66-81. http://www.scielo.org.co/scielo.php?script=sci_arttext\&pid=S012175502008000100007

Radnóti, S. (1999). The fake: Forgery and its place in art. Rowman \& Littlefield.

Ruiz Molina, F. (2020). Shanzhai. Apuntes para entender la explosión de la mercadería global pirata. En Olivia Dominguez (Comp.). Imaginarios transculturales. Culturas Urbanas Juveniles de Asia Oriental y su influencia en México. Palabra de Clío. Disponible en: https://palabradeclio.com.mx/pdf/detalle/Imaginarios_transculturales

Schwartz, H. (1996). The culture of the copie. Zone Books. New York.

Stallman, R. (1997). El derecho a la lectura en contra el copyright. Conaculta.

Stallman, R. (2002). Free software, free society. Selected essays of Richard M. Stallman. www.gnu.press

Steyerl, Hito (2012). Los condenados de la pantalla. Caja Negra.

Spragens, Th., A. (1999). Civic liberalism. Reflections on our democratic ideals. Rowman \& Littlefield.

Sundaram, R. (2010). Pirate modernity. Routledge.

Wu Ming (2002). Copyrighty maremoto en "Contra el copyright" (2008). CONACULTA.

Wu Ming (2003). El Copyleft explicado a niños en "Contra el copyright" (2008). CONACULTA.

Yang, Fan (2016). Faked in China. Nation branding counter culture and globalization. Indiana University. 